\title{
A Spectrophotometric Method for Diosmin Determination
}

\author{
Zenovia Moldovan ${ }^{1}$, Andrei A. Bunaciu² ${ }^{2}$ Mohammed A. Al-Omar ${ }^{3}$ and Hassan Y. Aboul-Enein ${ }^{*}, 3,4$ \\ ${ }^{1}$ Department of Analytical Chemistry, University of Bucharest, Bucharest, Romania \\ ${ }^{2}$ SC HOFIGAL SA, Analytical Research Department, 2 Intr. Serelor, Bucharest-4, 042124, Romania \\ ${ }^{3}$ Department of Pharmaceutical Chemistry, College of Pharmacy, King Saud University, Riyadh 11451, Saudi Arabia \\ ${ }^{4}$ Pharmaceutical and Medicinal Chemistry Department, National Research Centre, Dokki, Cairo, Egypt
}

\begin{abstract}
A rapid and sensitive spectrophotometric method for the determination of diosmin (D) has been developed. The method is based on the reaction of D with 4-aminoantipyrine (AAP) in the presence of hexacyanoferrate (III) (HCF) in an alkaline medium and subsequent formation of a purple coloured product having $\lambda_{\max }$ at $524.5 \mathrm{~nm}$. The conditions affecting the reaction (reagents concentration, $\mathrm{pH}$, order of addition of reagents, stability in time) were optimized. Under the optimum conditions, Beer's law was obeyed in the range of $0.3-35 \mu \mathrm{g} \mathrm{mL} \mathrm{m}^{-1} \mathrm{D}$ with a correlation coefficient of 0.9993 . The assay limits of detection and quantitation were 0.1 and $0.3 \mu \mathrm{g} \mathrm{mL} \mathrm{m}^{-1}$, respectively. The proposed method was successfully applied to the analysis of the drug tablets formulation. The results were compared favorably with those obtained by other reported methods.
\end{abstract}

Keywords: Flavone glycosides, diosmin, phlebotropic drugs, vitamin like substances, 4-aminoantipyrine, spectrophotometry.

\section{INTRODUCTION}

Phenolic compounds may occur in food plants as esters or glycosides conjugated with other natural compounds such as flavonoids, alcohols, hydroxyl fatty acids, sterols and glucosides [1].

Diosmin $\{\mathrm{D}$, (5-Hydroxy-2-(3-hydroxy-4-methoxyphenyl)7-[(2S,3R,4S,5S,6R)-3,4,5-trihydroxy-6-[[(2R,3R,4R,5R,6S)-3,4, 5-trihydroxy-6-methyloxan-2-yl] oxymethyl] oxan-2-yl]oxychromen-4-one) $\}$ is a semisynthetic phlebotropic drug (Scheme 1), a member of the flavonoid family, a naturally occurring flavone glycoside, used in the treatment of venous disease, i.e., chronic venous insufficiency (CVI) and hemorrhoidal disease (HD), in acute or chronic hemorrhoids, in place of rubber-band ligation, in combination with fiber supplement, or as an adjuvant therapy to hemorrhoidectomy, in order to reduce secondary bleeding $[2,3]$.

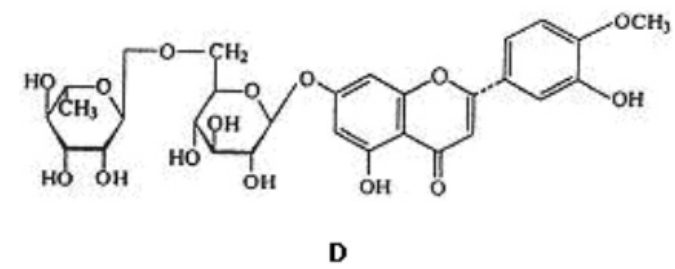

Scheme 1. Chemical structure of Diosmin.

Diosmin is used widely in Europe for decreasing the appearance of varicose veins and spider veins, and also hemorrhoids. Diosmin and other flavonoids thought to

*Address correspondence to this author at the Pharmaceutical and Medicinal Chemistry Department, Pharmaceutical and Drug Industries Research Division, National Research Centre, Dokki, Cairo 12311, Egypt; Tel: +20-2735-9209; Fax: +20-2-337-0597;

E-mails: hyaboulenein@yahoo.com; enein@gawab.com reduce capillary permeability and to have anti-inflammatory action were collectively known as vitamin $\mathrm{P}$, but these substances, however, are not vitamins.

Few analytical methods have been established for D determination and proposed for drug monitoring such as voltammetric [4], high performance liquid chromatography $[5,6]$, thin-layer chromatography $[7,8]$ or Fourier transform infrared spectrometry $[9,10]$ and spectrophotometric methods [7]. Because there are sensitive, convenient and relatively inexpensive, most of visible spectrophotometric methods are preferred for pharmaceutical determination. For this purpose, now we proposed a new spectrophotometric method based on the reaction of 4-aminoantipyrine (AAP) with $\mathrm{D}$ in the presence of potassium hexacyanoferrate (HCF).

\section{EXPERIMENTAL}

\subsection{Chemicals and Apparatus}

All chemicals were of analytical reagent grade. Potassium hexacyanoferrate $\left(\mathrm{K}_{3}\left[\mathrm{Fe}(\mathrm{CN})_{6}\right]\right.$, 99\%, Dagenham, $\mathrm{UK})$, boric acid $\left(\mathrm{Na}_{2} \mathrm{~B}_{4} \mathrm{O}_{7} \cdot 10 \mathrm{H}_{2} \mathrm{O}\right.$, Sigma-Aldrich, Exeter, UK), while potassium chloride and sodium hydroxide (Merck, Darmstadt, Germany). Diosmin standard was supplied by Fluka, Buchs-Switzerland; 4-aminoantipyrine was supplied by Chemos GmBH, Germany (min. 98\%) while the pharmaceutical formulation Dioven 500 (containing $500 \mathrm{mg}$ diosmin per tablet) was obtained from Amriya Pharmaceutical Industries International, Alexandria, Egypt. Doubly-distilled water was used throughout.

Eppendorf vary-pipettes (10-100; 100-1000 and 500$2500 \mu \mathrm{L})$ were used to deliver accurate volumes while the absorbance measurements were performed on a UV-VIS spectrophotometer LAMBDA 750 apparatus (Perkin Elmer Life and Analytical Sciences) using quartz cells of $1-\mathrm{cm}$ path length. The $\mathrm{pH}$ measurements were performed with a 
combined glass electrode (SP20B) connected to a multimeter Consort C830 (Consort-nv, Belgium).

A stock standard D solution $\left(200 \mu \mathrm{g} \mathrm{mL}^{-1}\right)$ was prepared by dissolving $20 \mathrm{mg} \mathrm{D}$ in $10 \mathrm{~mL}$ of $0.5 \mathrm{M} \mathrm{NaOH}$. The resulting solution was diluted with doubly-distilled water in a $100 \mathrm{~mL}$ volumetric flask. The solution was stored in a brown bottle and kept at $4^{\circ} \mathrm{C}$; it was used within two weeks of preparation.

A stock solution of AAP, $2 \times 10^{-2} \mathrm{~mol} \mathrm{~L}^{-1}$, was prepared by dissolving AAP and then diluting to the mark with doubly-distilled water in a $100 \mathrm{~mL}$ volumetric flask and kept at $4{ }^{\circ} \mathrm{C}$, when not in use. The solution was stable for at least 2 months.

A stock solution of $\mathrm{HCF}, 4 \times 10^{-2} \mathrm{~mol} \mathrm{~L}^{-1}$, was prepared by dissolving $0.6585 \mathrm{~g}$ of potassium hexacyanoferrate in 50 $\mathrm{mL}$ aqueous solution.

Borate buffers (B), (pH 9; 9.4; 9.8; 10.2; 10.6; 11) were prepared by dissolving calculated amount of boric acid and potassium chloride in deionized water. A $0.2 \mathrm{~mol} \mathrm{~L}^{-1}$ sodium hydroxide solution was used to adjust the $\mathrm{pH}$ of prepared buffers. A $0.5 \mathrm{~mol} \mathrm{~L}^{-1}$ aqueous solution of $\mathrm{NaOH}$ was also prepared. Required working standard solutions were prepared by diluting the corresponding stock solutions.

\subsection{General Procedure}

For optimizing of every reagent concentration, $0.15 \mathrm{~mL}$ of the standard solution containing $30 \mu \mathrm{g}$ of D was directly put into a glass cuvette, followed by the addition of $0.8 \mathrm{~mL}$ of buffer solution, doubly-distilled water and aliquots of AAP and HCF solutions having different concentrations to make the volume to $2 \mathrm{~mL}$. As soon as HCF was added, the cuvette was covered with cuvette lid; after that the solution was quickly shaken and placed in the spectrophotometer cell holder using exactly time $15 \mathrm{~s}$. Then, absorbance was measured at $\lambda=524.5 \mathrm{~nm}$ against reagent blank as reference. The dependence of reagents concentrations on the absorbance was studied in the following ranges: [AAP] = $(1.0-3.5) \times 10^{-3} \mathrm{~mol} \mathrm{~L}^{-1},[\mathrm{HCF}]=(2.0-7.0) \times 10^{-3} \mathrm{~mol} \mathrm{~L}^{-1}$. A calibration graph was constructed, under optimum working conditions, by plotting the absorbance of coloured compound, as a function of diosmin concentration. The D content of the synthetic or real samples was determined from the calibration graph; the mentioned samples were prepared according to the general procedure.

\subsection{Procedure for Determination of Diosmin in Real Sample}

Ten tablets of Dioven were weighed (mean $9.3428 \mathrm{~g}$ ) and grinded into fine powder. From this powder, five accurately weighed portions were obtained. After dissolution of the active principle in $5 \mathrm{~mL}$ of $\mathrm{NaOH} 0.5 \mathrm{M}$, each sample was filtered and quantitatively transferred into $50 \mathrm{~mL}$ calibrated flask, with doubly-distilled water. Known volumes of samples solutions $(0.1 \mathrm{~mL})$ were analyzed by the proposed spectrophotometric method.

\subsection{Recovery}

Known amount of drug powder $(20 \mathrm{mg})$ equivalent to 10 $\mathrm{mg}$ of $\mathrm{D}$ was weighed accurately. After dissolution of the active principle in $5 \mathrm{~mL}$ of $\mathrm{NaOH} 0.5 \mathrm{M}$, the sample was filtered and quantitatively transferred into a $50 \mathrm{~mL}$ calibrated flask, with doubly-distilled water. Then, known volumes $(0.1$ $\mathrm{mL})$ of the stocks standard solution of pure D $\left(200 \mu \mathrm{g} \mathrm{mL} \mathrm{m}^{-1}\right)$ were added to known volumes $(0.1 \mathrm{~mL})$ of the sample solution and the general procedure applied.

\section{RESULTS AND DISCUSSION}

The reaction with AAP in the presence of an oxidant such as hexacyanoferrate (III) in alkaline solution is one of the most widely used reactions for the determination of phenols. On the basis of literature data [11], the mechanism of such a reaction seems to be as follows (Scheme 2).

As stated earlier, D molecule provides phenolic groups that can react with the mentioned chromogenic reagent (AAP), resulting in a chromophore, thus enabling a quantitative method to be developed. The wavelength of maximum absorbance attributed to the resulted quinoneimine was found to be at $524.5 \mathrm{~nm}$, whereas the D exhibited their two absorption maxima at 263.5 and $360 \mathrm{~nm}$, under the same experimental conditions (Fig. 1).

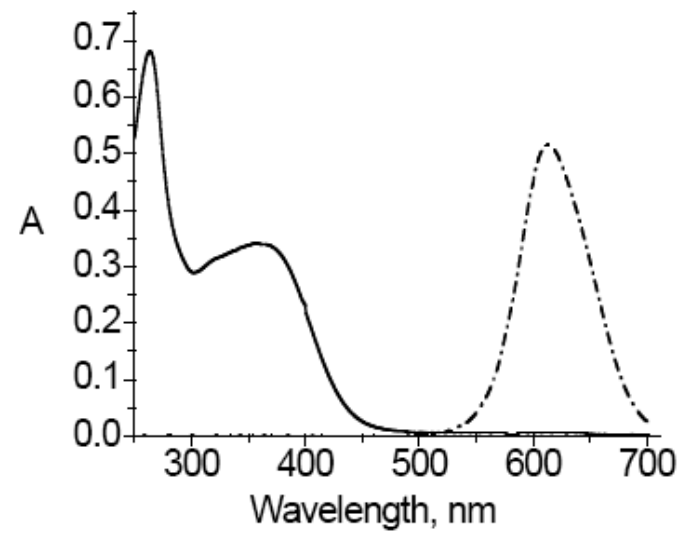

Fig. (1). UV-VIS spectra of Diosmin (straight line) and D-AAPHCF complex (dash dot line). $\left.[\mathrm{D}]=15 \mu \mathrm{g} \mathrm{mL}^{-1} ; \mathrm{HCF}\right]=5 \times 10^{-3}$ $\mathrm{mol} \mathrm{L}{ }^{-1} ;[\mathrm{AAP}]=2.5 \times 10^{-3} \mathrm{~mol} \mathrm{~L}^{-1}$.

Preliminary experiments showed that the position of its characteristic band does not change while varying the $\mathrm{pH}$, in the range 9-11, and reagent's concentrations. The main

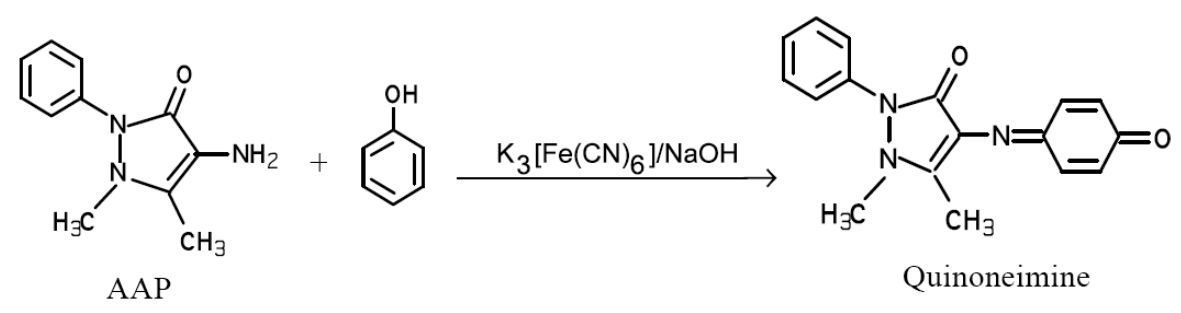

Scheme 2. Proposed reaction between AAP and phenol. 
parameters that can influence the performance of the proposed method were studied to reach the optimum working configuration.

\subsection{Effect of AAP and HCF Concentration}

An important factor that must be taken into account involves the concentration ratio of AAP and the oxidizing agent $[12,13]$. At a constant concentration of AAP $\left(2.5 \times 10^{-}\right.$ $\left.{ }^{3} \mathrm{~mol} \mathrm{~L}^{-1}\right)$, the concentration of $\mathrm{HCF}$ was varied in the following range: $2.5 \times 10^{-3}-5.5 \times 10^{-3} \mathrm{~mol} \mathrm{~L}^{-1} \mathrm{As}$ is shown in Fig. (2), in presence of $15 \mu \mathrm{g} \mathrm{mL}^{-1} \mathrm{D}$ the absorbance of the reaction product increases with increasing concentration of $\mathrm{HCF}$, reaching the maximum value for the ratio AAP : HCF $=1: 2$. This behavior is in accordance with the mechanism of the coupling reaction between $\mathrm{HCF}$ and AAP which involves two electrons transfer from the nitrogen atom of AAP to two molecules of potassium hexacyanoferrate (III) [10].

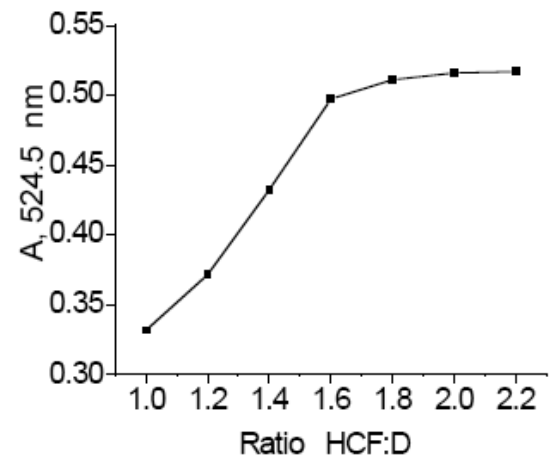

Fig. (2). Variation of absorbance with ratio HCF: AAP. [D] $=15 \mu \mathrm{g}$ $\mathrm{mL}^{-1} ;[\mathrm{HCF}]=(2.5-5.5) \times 10^{-3} \mathrm{~mol} \mathrm{~L}^{-1} ;[\mathrm{AAP}]=2.5 \times 10^{-3} \mathrm{~mol} \mathrm{~L}^{-1}$.

The following step was to prepare different mixtures having the same ratio AAP : $\mathrm{HCF}=1: 1$, but at different level of AAP and HCF concentrations. For this purpose, the concentration of AAP was varied in the range: $1 \times 10^{-3}-3.5$ $\times 10^{-3} \mathrm{~mol} \mathrm{~L}^{-1}$ and of HCF, in the range: $2 \times 10^{-3}-7 \times 10^{-3}$ mol $\mathrm{L}^{-1}$. The absorbance increases with AAP and $\mathrm{HCF}$ concentration up to $2.5 \times 10^{-3} \mathrm{~mol} \mathrm{~L}^{-1}$ for AAP and $5 \times 10^{-3}$ mol L ${ }^{-1}$ for HCF, then it remains almost constant (Fig. 3). Therefore, these concentrations of AAP and HCF were used in the recommended procedure.

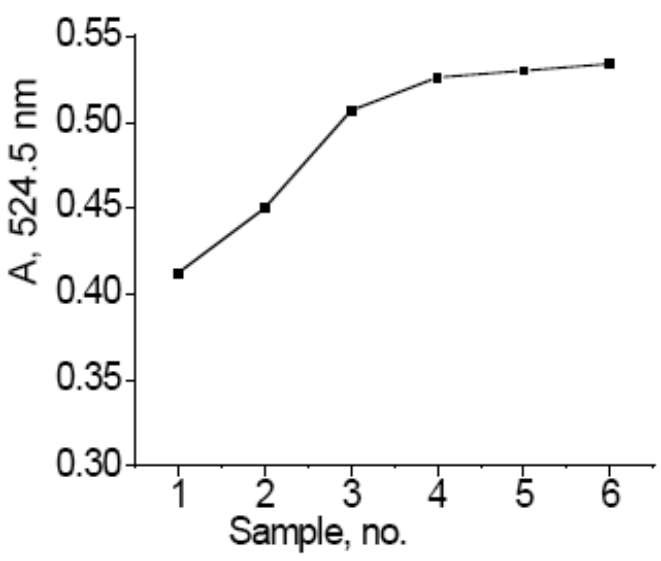

Fig. (3). Variation of absorbance with concentration of HCF and $\mathrm{AAP}$, at ratio $\mathrm{HCF}: \mathrm{AAP}=2: 1 .[\mathrm{D}]=15 \mu \mathrm{g} \mathrm{mL}^{-1} ;[\mathrm{HCF}]=(2 ; 3 ; 4$; $5 ; 6 ; 7) \times 10^{-3} \mathrm{~mol} \mathrm{~L}^{-1} ;[\mathrm{AAP}]=(1 ; 1.5 ; 2 ; 2.5 ; 3 ; 3.5) \times 10^{-3} \mathrm{~mol} \mathrm{~L}^{-1}$.

\subsection{Effect of $p H$}

The effect of $\mathrm{pH}$ was investigated in the range 9 - 11 . The maximum absorbance of the reaction product was reached at $\mathrm{pH}=9.4$ (Fig. 4). At $\mathrm{pH}$ values above this, a significant decrease in absorbance is observed. The following experiments were performed at $\mathrm{pH} 9.4$.

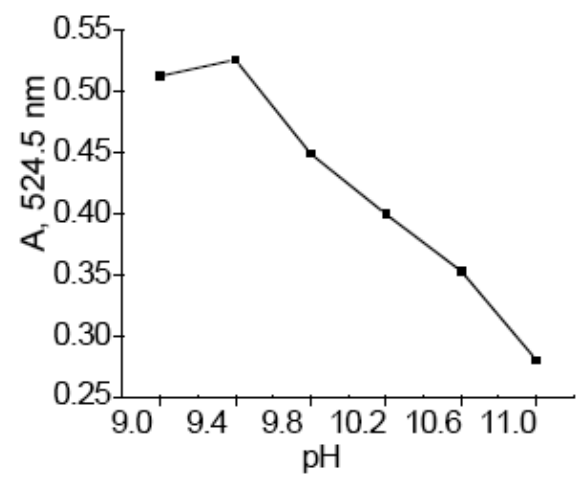

Fig. (4). Variation of absorbance with $\mathrm{pH}$. [D] $=15 \mu \mathrm{g} \mathrm{mL} \mathrm{m}^{-1}$; $[$ AAP $]=2.5 \times 10^{-3} \mathrm{~mol} \mathrm{~L}^{-1} ;[\mathrm{HCF}]=5 \times 10^{-3} \mathrm{~mol} \mathrm{~L}^{-1}$.

\subsection{Order of Addition of Reactants}

The sequence of addition of reactants can influence the formation of coloured product $[12,13]$. Four procedures with different orders of component addition were examined. Thus, the sequence (1) D-B-AAP-HCF gave higher values of absorbance. When mixing AAP and HCF (sequence 2), a red colour solution is obtained before adding $\mathrm{D}$ and $\mathrm{B}$, probably due to the generation of antipyrine red $[12,13]$. The sequence (3) B-D-HCF-AAP gave an absorbance less by half than in the case of sequence (1). The sequence (4) BHCF-AAP-D gave an insignificant absorbance in the studied range.

This behavior should be explained as follows: the amino group of AAP is oxidised by $\left[\mathrm{Fe}(\mathrm{CN})_{6}\right]^{3-}$ to an imino cation which could be leads, in alkaline medium, to a stable derivative of AAP, unable after that to react with diosmin. Fig. (5) presents the variation of absorbance with reactants addition order and taking into account the higher values of absorbance the sequence (1) was chosen to be applied in the proposed method. The mechanism of reaction was explained earlier [12].

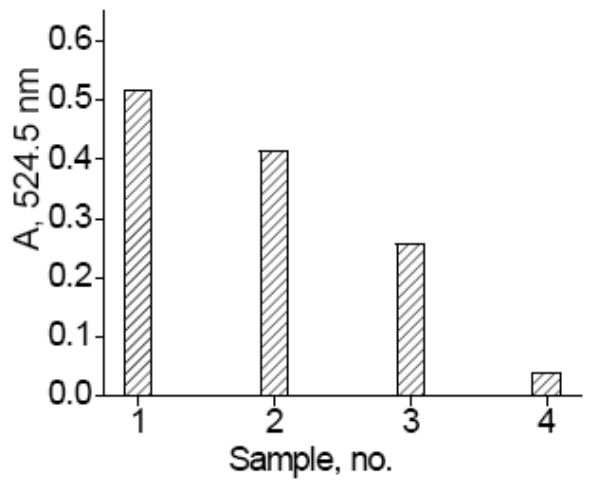

Fig. (5). Variation of absorbance with reactants addition order. (1) D-B-AAP-HCF; (2) AAP-HCF-D-B; (3) B-HCF-D-AAP; (4) B-D-HCF-AAP. [D] $=15 \mu \mathrm{g} \mathrm{mL}^{-1}$; [AAP $]=2.5 \times 10^{-3} \mathrm{~mol} \mathrm{~L}^{-1}$; $[\mathrm{HCF}]=5 \times 10^{-3} \mathrm{~mol} \mathrm{~L}^{-1}$. 


\subsection{The Stability of Coloured Reaction Product in Time}

A slowly decreasing of the absorbance of reaction product takes place. Because of this progressive colour reduction, which results in a decrease in absorbance $(\sim 32 \%$, after $1000 \mathrm{~s}$ from reaction initiation), it is recommended to measure the absorbance immediately or at a constant short time interval after colour development. For this reason, the experiments were made as follows: the standard solution containing diosmin was directly pipetted into a glass cuvette, followed by the addition of $0.8 \mathrm{~mL}$ of buffer solution, doubly-distilled water and AAP. As soon as HCF was added (making the total volume to $2 \mathrm{~mL}$ ), the cuvette was covered with cuvette lid; after that the solution was quickly shaken and placed in the spectrophotometer cell holder using exactly time $15 \mathrm{~s}$.

\subsection{Analytical Figures of Merit}

Once the optimum working conditions were established, the proposed spectrophotometric method was evaluated with respect to linearity, LOD, LOQ, accuracy, precision. The performances of the proposed method were verified on samples having the following composition and respecting this order of reagents addition: a sample solution containing a known amount of $\mathrm{D}+0.8 \mathrm{~mL}$ of $\mathrm{B}(\mathrm{pH} 9.4)+0.25 \mathrm{~mL}$ of $2 \times 10^{-3} \mathrm{~mol} \mathrm{~L}^{-1}$ AAP + doubly-distilled water $+0.25 \mathrm{~mL}$ of $4 \times 10^{-3} \mathrm{~mol} \mathrm{~L}^{-1} \mathrm{HCF}$ (total volume $2 \mathrm{~mL}$ ).

The calibration graph was plotted by use of absorbance values obtained from five replicate samples of same diosmin content. The linear regression equation was as follows:

$A_{524.5 \mathrm{~nm}}=0.0318[\mathrm{D}]+0.0227$

where [D] is the diosmin concentration expressed in $\mu \mathrm{g} \mathrm{mL} \mathrm{m}^{-}$ 1; the squared correlation coefficient, $r^{2}=0.9993$; the detection limit, LOD (calculated as three times the standard deviation of the blank) $=0.1 \mu \mathrm{g} \mathrm{mL}^{-1} \mathrm{D}$ and LOQ $=0.3 \mu \mathrm{g}$ $\mathrm{mL}^{-1}$ D. LOQ was considered as the lowest calibration standard which was approximately equal to the calculated 10 times the standard deviation of the results for the series of replicates used to determine the limit of detection. The proposed spectrophotometric method permits determination of diosmin over the range $0.30-35 \mu \mathrm{g} \mathrm{mL}{ }^{-1}$ The molar absorptivity coefficient of the reaction product was found to be $2.09 \times 10^{4} \mathrm{~L} \mathrm{~mol}^{-1} \mathrm{~cm}^{-1}$. In order to estimate the accuracy and precision of the proposed method, standard solutions of 5; 15 and $25 \mu \mathrm{g} \mathrm{mL} \mathrm{m}^{-1} \mathrm{D}$ were analyzed according to the recommended procedure. For this purpose, six replicate determinations of each concentration were prepared. As can be seen in Table 1 , the percent recovery ranged $100.20 \%$ to $100.55 \%$ from the labeled amount, while the relative standard deviations ranged from $0.65 \%$ to $2.16 \%$.

Table 1. Precision and Accuracy of the Proposed Method

\begin{tabular}{|c|c|c|c|}
\hline \multicolumn{2}{|c|}{ Diosmin, $\mu \mathrm{g} \mathrm{mL}^{-1}$} & \multirow{2}{*}{$R S D, \%$} & \multirow{2}{*}{$R, \%$} \\
\hline Taken & ${ }^{*}$ Found $\pm t S N^{-0.5}$ & & \\
\hline 5 & $5.01 \pm 0.11$ & 2.16 & 100.20 \\
\hline 15 & $15.08 \pm 0.23$ & 1.48 & 100.55 \\
\hline 25 & $25.11 \pm 0.17$ & 0.65 & 100.43 \\
\hline
\end{tabular}

*Mean $\pm 95 \%$ confidence limit, for $N=6 ; t=2.57$ = t-distribution for confidence level of $95 \%$ with $N-1$ degrees of freedom.

$R S D=$ Relative standard deviation; $R, \%=$ percent recovery

\subsection{Interferences}

Effects of some possible excipients in commercial formulation (microcrystalline cellulose, polyvinylpolypyrrolidone (povidone), stearic acid) were investigated. The maximum ratio of interfering species to the analyte concentration was chosen to be $1: 2$ because these preservatives must not be used over this ratio. The result showed that these excipients had no significant effect on the determination of diosmin since they were insoluble in alkaline medium and were removed in the filtration step.

\subsection{Analysis of Diosmin in Dosage Form}

For verifying the efficiency of the proposed method, it was applied on a real sample with a known content of diosmin, namely Dioven (containing $500 \mathrm{mg}$ diosmin/tablet). The results in Table 2 demonstrate the precision of the proposed spectrophotometric method. The diosmin content $(\mathrm{mg})$ in the tested sample solution obtained by the proposed method $(100.88 \pm 2.74 \%)$ is in accord with the reported (99.6 $\pm 2.1 \%)$ and the official $(99.2 \pm 2.4 \%)$ assay methods $[6,14]$.

Accuracy and reliability of the proposed method were further ascertained by performing recovery experiments. To a fixed amount of the drug in formulation (pre-analysed), pure diosmin at three different levels of concentration was added, and the total was determined by the proposed method. Each test was repeated three times. The results compiled in Table 3 show that recoveries were in the range 101.64 $101.89 \%$ indicating that commonly added excepiens in the drug did not interfere in the spectrophotometric determination of the active principle.

Table 2. Determination of Diosmin Content in Dioven Tablets Using the Proposed Spectrophotometric Method

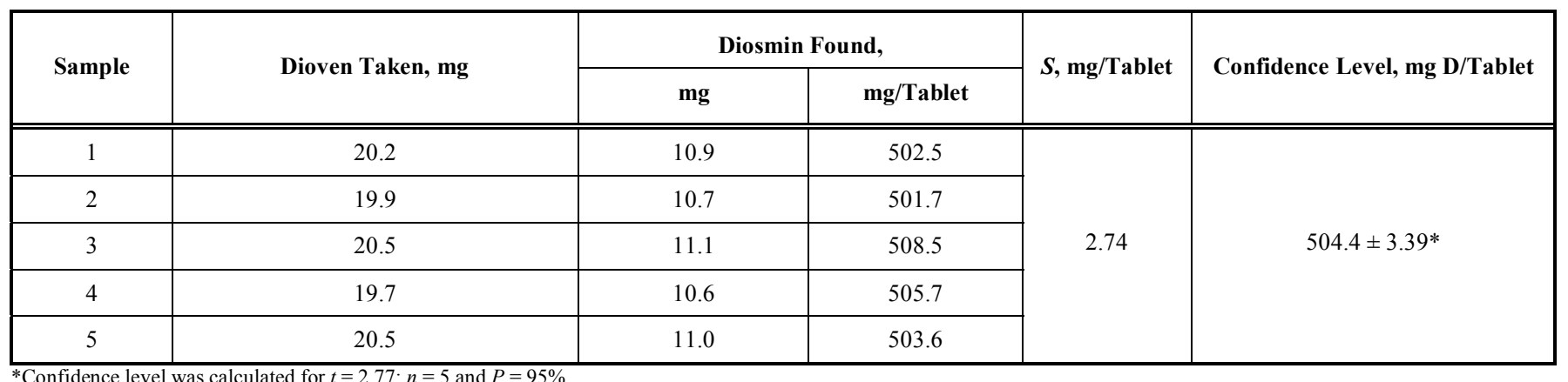

*Confidence level was calculated for $t=2.77 ; n=5$ and $P=95 \%$. 
Table 3. Results of Recovery Study Using Standard-Addition Method

\begin{tabular}{|c|c|c|c|c|}
\hline $\begin{array}{c}\text { Dioven } \\
\text { Taken, } \\
\boldsymbol{\mu g}\end{array}$ & $\begin{array}{c}\text { D Added, } \\
\boldsymbol{\mu g}\end{array}$ & $\begin{array}{c}\text { D Found, } \\
\boldsymbol{\mu g}\end{array}$ & $\begin{array}{c}\text { Amount of } \\
\text { D Added* } \pm \boldsymbol{S}, \boldsymbol{\mu g}\end{array}$ & $\begin{array}{c}\text { Recovery of } \\
\text { D Added, } \%\end{array}$ \\
\hline \hline 20 & - & 21.73 & - & - \\
\hline 20 & 5.0 & 26.82 & $5.09 \pm 0.09$ & 101.89 \\
\hline 20 & 10.0 & 31.96 & $10.23 \pm 0.04$ & 102.33 \\
\hline 20 & 15.0 & 47.21 & $15.25 \pm 0.06$ & 101.64 \\
\hline
\end{tabular}

\section{CONCLUSION}

The reaction between diosmin and 4-aminoantipyrine in presence of hexacyanoferrate (III), in alkaline medium, is an analytical reaction that can be applied in the spectrophotometric determination of diosmin-containing drugs. The proposed method is inexpensive, fairly rapid and sensitive. The analytical parameters, sensitivity, precision, accuracy, rapidity, recommend the proposed method as an alternative to other reported methods as an instrument for quality control of drugs containing diosmin.

\section{REFERENCES}

[1] Naczk, M.; Shahidi, F. Phenolics in cereals, fruits and vegetables: Occurrence, extraction and analysis. J. Pharm. Biomed. Anal., 2006, 41,1523 .

[2] Vertommen, J.; van den Enden, M.; Simoens, L.; de Leeuw, I. Flavonoid treatment reduces glycation and lipid peroxidation in experimental diabetic rats. Phytother. Res., 2006, 8, 430.

[3] Dugo, P.; Presti, M.L.; Ohman, M.; Fazio, A.; Dugo, G.; Mondello, L. Detemination of flavonoids in citrus fruits juices by microHPLC-ESI/Ms. J. Sep. Sci., 2005, 28,1149.
[4] El-Shahawi, M.S.; Bashammakh, A.S.; El-Mogy, T. Determination of trace levels of diosmin in a pharmaceutical preparation by adsorptive stripping voltammetry at a glassy carbon electrode. Anal. Sci., 2006, 22, 1351.

[5] Campanero, M.A.; Escolar, M.; Perez, G.; Garcia-Quetglas, E.; Sadaba, B.; Azanza, J.R. Simultaneous determination of diosmin and diosmetin in human plasma by ion trap liquid chromatography-atmospheric pressure chemical ionization tandem mass spectrometry: Application to a clinical pharmacokinetic study. J. Pharm. Biomed. Anal., 2010, 51,875.

[6] El-Shafae, A.M.; El-Domiaty, M.M. Improved LC methods for the determination of diosmin and/or hesperidin in plant extracts and pharmaceutical formulations. J. Pharm. Biomed. Anal., 2001, 26, 539.

[7] El Bayoumi, A. Modified H-point standard addition method and logarithmic function for the spectrophotometric and spectrodensitometric determination of hesperidin and diosmin in mixtures. Anal. Lett., 1999, 32, 383.

[8] Janeczko, Z.; Hubicka, U.; Krzek, J.; Podolak, I. Qualitative and quantitative analysis of diosmin in tablets by thin-layer chromatography with densitometric UV detection. J. Planar Chromatogr.-Modern TLC, 2003, 16, 377.

[9] Melin, A.; Perromat, A.; Deleris, G. Fourier-transform infrared spectroscopy: A pharmacotoxicologic tool for in vivo monitoring radical aggression. Can. J. Physiol. Pharmacol., 2001, 79, 158.

[10] Bunaciu, A.A.; Udristioiu, G.E.; Ruta, L.L.; Fleschin, S.; AboulEnein, H.Y. Determination of diosmin in pharmaceutical formulations using Fourier transform infrared spectrophotometry. Saudi Pharm. J., 2009, 17, 303.

[11] Beyene, N.W.; Van Staden, J.F.; Stefan, R-I.; Aboul-Enein, H.Y. Determination of isoxsuprine hydrochloride by sequential injection visible spectrophotometry. Farmaco, 2005, 60, 613.

[12] Fiamegos, Y.C.; Stalikas, C.D.; Pilidis, G.A.; Karayannis, M.I. Synthesis and analytical applications of 4-aminopyrazolone derivatives as chromogenic agents for the spectrophotometric determination of phenols. Anal. Chim. Acta, 2000, 403, 315.

[13] Svobodova, D.; Gasparic, J. Investigation of the colour reaction of phenols with 4-aminoantipyrine. Microchim. Acta, 1971, 2, 384.

[14] Kanaze, F.I.; Gabriele, C.; Kokkalou, E.; Georgarakis, M.; Niopas, I. Simultaneous reversed-phase high-performance liquid chromatographic method for the determination of diosmin, hesperidin and naringin in different citrus fruit juices and pharmaceutical formulations. J. Pharm. Biomed. Anal., 2003, 33, 243. 